Baranauskas, 2013; Esjeholm, 2014; Karapanos, 2013; Woods et al., 2014).

It should also be noted the relevance of researches that envisage the Experiential Design and its focus and emphasis on the people who use the technologies, i.e., the users. That's why this article aims to direct the attention, not the theoretical inputs that substantiate this perspective and are highlighted in the literature, but to the outlines and practices of design that come together to reach those inputs.

Efforts toward the gathering, analysis and evaluation of heterogeneous data, derived from the interaction of users with a myriad of different technologies and proposed solutions have waken the attention of researchers and directed their efforts towards a consolidation of the area, in different aspects in the project's process (Hartson \& Pyla, 2012; Unger \& Chandler, 2012), in the implementation of specific methodologies (Brown, 2013; Gothelf, 2013), in methods of assessment (Law et al., 2009, 2014) or by proposing maturity models that better orient organizations towards the practice of UXD (Carraro, 2006).

However, it is relevant to have a clear picture of the initial design of the interdisciplinary teams involved in the process of the UX project based on semantics that depict what is intended to be implemented in organizations, and that are in line with its goals and use the possibilities that arise from the UX assessments, given its existence in an organizational environment, since the international literature describes, significantly, the contributions from UX evaluations for the project' process by considering that they are not only restricted to the assessments of usability (Hayashi \& Baranauskas, 2013; Pereira \& Baranauskas, 2015; Law et al., 2014; Karapanos, 2013).

Based on it, Law et al. (2014) highlights that measuring is important, but insufficient, and becomes more useful when the structural models are oriented towards clarifying the variables related to UX, thus favoring the visibility of the project's process in its inception. In this regard, the structures are necessary for establishing the causal relations among the variables coming from the UXD, whereby the conception of dynamic models not only supports the construction of theories, but also orient teams towards the development and sizing of the variables that outline the project's process, thus establishing an effective communication among the people involved in the process (Law et al., 2009, 2014; Walsh, 2014).

In view of the above, this article presents theoretical and practical support by depicting efforts of DAfetU systemic modelling, a hybrid framework oriented to the assessment of the impact coming from interactive computational systems (Ellwanger et al., 2014, 2015), aiming to explore the possibilities of modelling and simulation for collaboration among interdisciplinary teams for a better understanding of the initial designs related to UXD.

\section{Preliminary designs of the Design Process}

The project's process, or Design Process (DP), is not only established by the artifact or service generated by this process, but also, by the understanding of the human needs and aspirations in a given usability context as well as in the process of verifying how the conceptualized solutions back up those needs. This is defined by a series of transformations among the different stages of information, or knowledge that underpin the resolution of a problem and is structured by distinct phases, or stages, whereby actions and procedures present themselve in a systematic form, thus replacing the intuition and the disorganized experimentation (Welch \& Dixon, 1992; Suh, 1990).

These aspects demonstrate the importance of Planning in the project's process, because by doing so the process can be controlled, thus favoring any potential detour in the path and the verification of the project's success (Fiod, 1993). With that in mind, the conception of ideas is an integral part of the creative problem solution (CPS), and essential to the project's process because it considers a group of decisions whose goal is to transpose the immaterial, the idea, the plan, the imaginary and the abstract to the real, the concrete and the explicit where the solutions can be visualized and established by means of formal procedures (Calvera, 2006).

Herring et al. (2009) highlights that the ideation is a mix of research, representation and refinement (cf. Figure 1), whereby the research means the constant search for a better understanding of the domain of the problem, which results in divergent concepts that, afterwards, represent themselves in a way (usually quick sketches) that can be shared, and can help in the verification of which concepts can be discarded, or refined (convergence of concepts by the Designer).

Refined and validated concepts drive future researches and the acquisition of new knowledge through a cycle of continuous improvement that shapes everything that is understood of a specific situation, i.e., a group of decisions that delineates the project as a whole. However, it is not always possible to have a correct measurement of those decisions and their impacts because the method and the unexpected follow one another and complement each other during the designing activities.

Morin (2000) highlights that, when designers/draftsman are involved in a given project, even though they follow a specific methodology, oftentimes they are faced with the presence of unknown or aleatory 


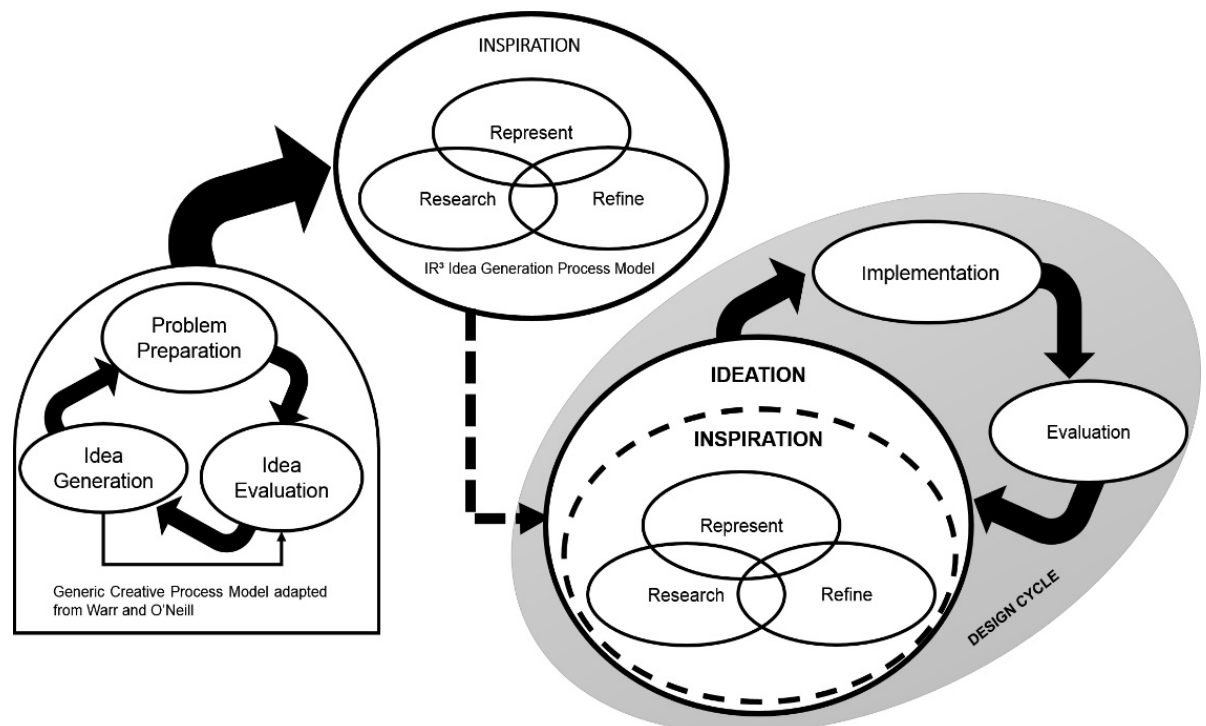

Figure 1. Ideas Generation Process. Source: Adapted from Herring et al. (2009).

points, and this can positively contribute for the development and the solution of the project because the unknown factors can establish connections that previously were not visible.

Even though the discovery of those connections may surprise some designers, they take the shape of new a logic or new way of understanding and seeing things (Ostrower, 1990). The author adds that these are "inspiring" moments, where "[...] suggestions, propositions, assessments and emotions coalesce and, consequently, everything is reformulated" (Ostrower, 1990, p. 19). However, the inspiration does not happen in a chaotic way, but guided by a methodology that orients the project, whereby the role of the inspiration is to show the possible way.

Speaking about the methodology of the project, Munari (1998) highlights that the methods should not be set as absolute or final because they can be altered if the designer identifies elements that can improve the process. The words of Burdek (2006, p. 225) reinforce this way of thinking by also highlighting that Design is a creative process, whereby

[...] each object of design is a result of a development process whose progress is determined by conditions and decisions, and not only by configuration.

Thus, the rules of the method do not hinder the personality of the designer, but rather encourage him to discover things that are also useful to other people too. In addition, the unknown factors are a result of the ongoing project and the expectations of the designer himself, either if he is aware of it or not (Munari, 1998). These premises lead to the project's process to the user experience.

\section{Project's process to the user experience: the merging of an area}

The process of projecting for the user experience (UXD), also called Experience Design, presents itself as a structure that orients professionals, either new ones or specialists, about the complex details of a project whose philosophy is the design centered in the user, thus helping him to check where he is at any given moment and what must be done in that specific situation.

Through this, the professionals /novices process can best target the design of quality products and verify how much they evolve in terms of expertise, while for specialists, the process presents itself as a form of verification that certifies them of the important aspects of the problems, that are being pushed aside at the expense of productivity (Hartson \& Pyla, 2012). Therefore, Hartson \& Pyla (2012), emphasize that UXD consists of an iterative and interactive cycle formed by the stages of Analysis, Design, Prototyping and Evaluation, shown in Figure 2.

The Analysis phase comprises a number of subactivities that include investigations and analysis of the user / client context and their work practices "in loco"; the extraction of requirements, from contextual data, or the design informed by means of models. Initial investigations and analyzes allow inferring user needs in new system designs. The extraction of requirements relates to interaction design requirements, guide the project process and help determine their characteristics in visual, sentimental and behavioral terms.

In addition, requirements are used as a checklist to ensure that they are included in the project, before any UX evaluation is performed. The project informed by 


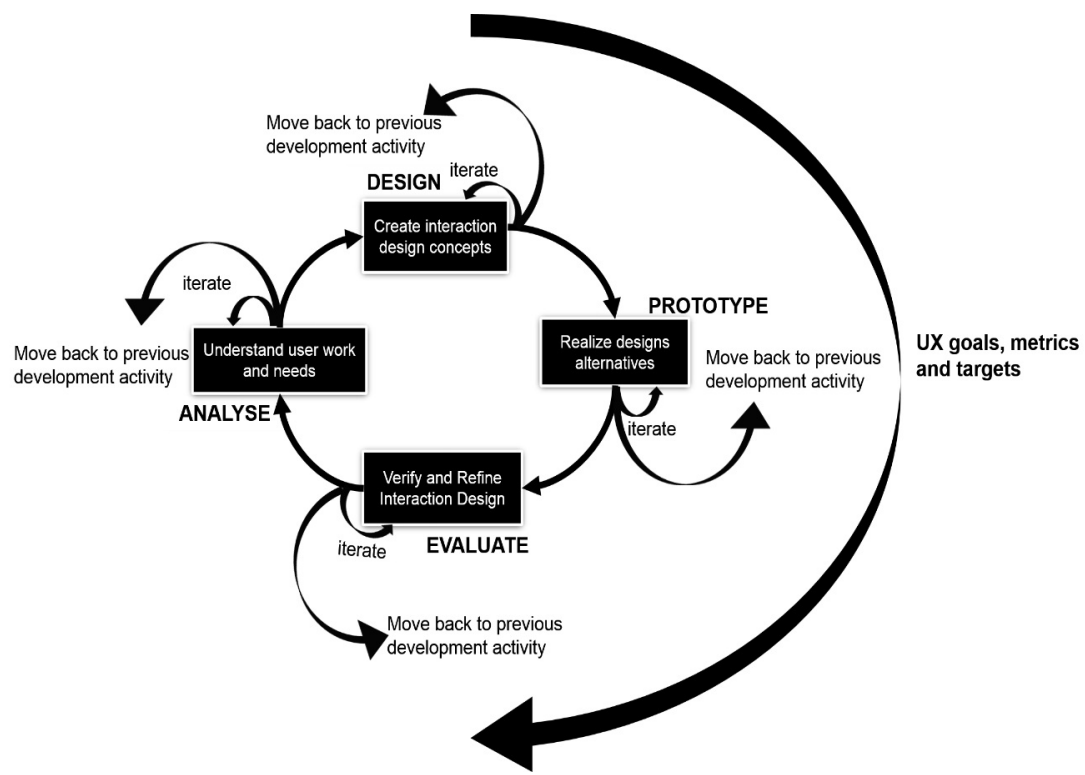

Figure 2. Process of UX. Source: Adapted of Hartson \& Pyla (2012).

means of models consists of abstractions of different dimensions of the work activity and the space of the project. Its use includes templates that describe how things are do and how different working rules are reflected in the interaction and artifacts created.

The Design phase involves the creation of conceptual design, the form of interaction and the look and feel, including the redesign of versions. Its subactivities are the ideation and development of initial sketches (sketching). Ideation leads to modeling, concept and user stories, and can include a large number of mockups from the initial ideas. Production is a subset of the Design step and involves detailing how requirements are applied, how the models inform the design and reflection of how these models can direct and inform the emerging need for interaction design. Thus, production leads to prototyping, the interaction of the conceptual design, the intermediate designs and the detailing of the project.

The Prototyping phase occurs in parallel and in conjunction with the design phase and directs the production of several types of prototypes, considering that they can be developed for different purposes and at different levels of fidelity (low, medium and high), including in these cases the paper prototypes, the functional prototypes and also the visual compositions for the structuring of the look and feel, while the Evaluation phase is driven by the use of rapid or rigorous evaluation methods. From them it is possible to verify the alignment between goals and UX metrics related to the use and business objectives (ISO, 1999).

Drahun (2016) present a collection of different visual definitions that depict concepts related to the user experience (UX). For the scope of this work, one of these definitions stands out among the others, for linking user experience to a system, consisting of a set of steps that feed back (cf. Figure 3), in which pragmatic and hedonic aspects are contemplated and established as proposals of value corresponding to the scope of UXD and under the perception of users towards these values.

Both this approach and the Hartson \& Pyla (2012) portray how the design process is reconstituted through the steps that make up a systemic bias. However, Hartson \& Pyla (2012) emphasize the importance of metrics to guide the process as a whole. They also asserted that the agreement on the use of metrics is important for the alignment of organizational processes, since many times, unconsciously, teams may become distracted and disregard certain information because they do not perceive that they are solving different problems. Clear goals guided by a specific set of metrics can favor the alignment of teams towards achieving the same goal.

In the sense of King \& Churchill (2015), the definition of common metrics also helps teams stay focused on what really matters, because additional reflections can come from adding value to the user/customer experience in which an asset is added, a characteristic, enhancement of a characteristic, and later improvement of improvement. Thus the lack of discipline in terms of how these improvements correlate clearly leads to their original purpose, leading to stagnation of the process. The authors also point out that clear metrics also allow consistency over time, because they should not be changed at all times, occasionally change, but the ideal is that this is an exception and not the rule. 


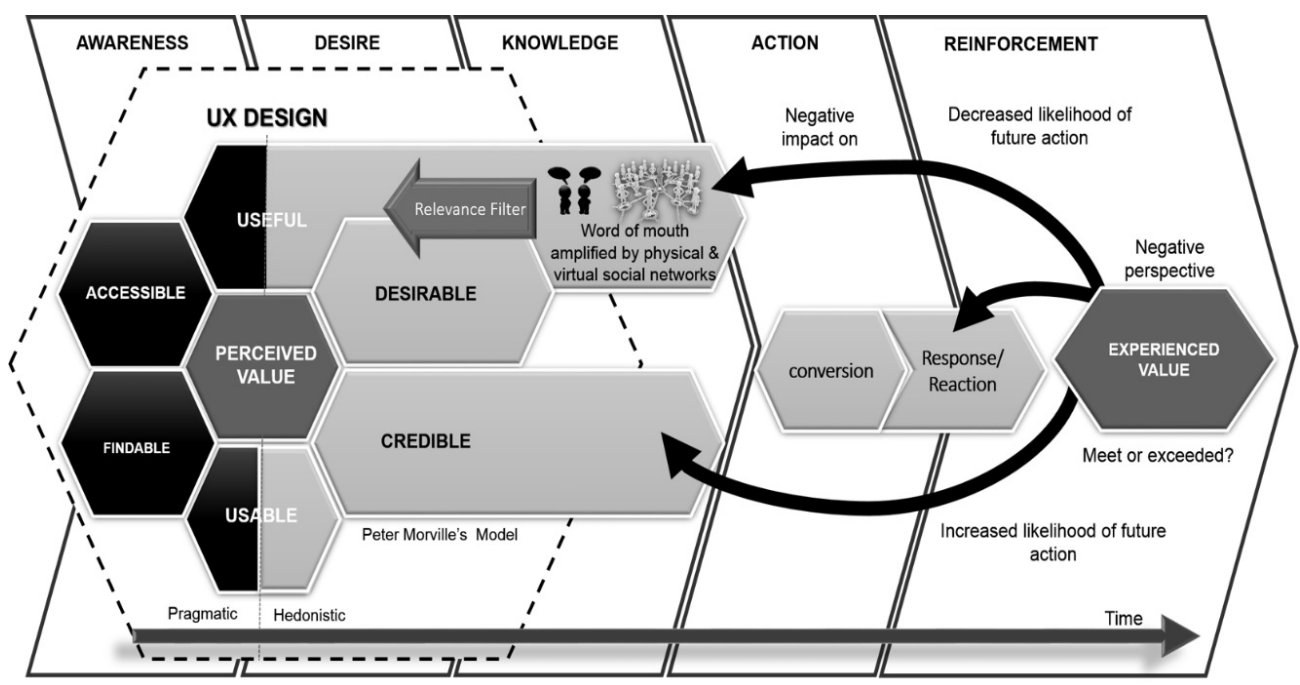

Figure 3. Ecosystem of UXD. Source: Adapted of Drahun (2016).

Initial explorations (surveys) of project associated with a consistent set of metrics favor an understanding of the expected impact, given some changes in the project. In addition the results of a project can be compared with others, because metrics subsidize the ideation. By knowing and understanding which metrics should be contemplated in a given project, the impact of certain ideas and how important they become are more clearly perceived. Project explorations evaluated from common metrics make it possible to compare these explorations with one another, in terms of impact and, at the same time, provide a basis for their balanced judgment (King \& Churchill, 2015).

In addition to these assumptions, the establishment of a process becomes important for the organizational memory, because it portrays previous efforts, similar or discrepant, that outline the lessons learned that can be replicated. In addition, clear processes minimize the risks related to them by explaining what is being developed, making it possible to be observed, measured, analyzed and controlled, otherwise, the communication between the functions of those involved in the project, becomes difficult, because there is no consensus on what should be done (Hartson \& Pyla, 2012).

Carraro (2006) points out that many companies have limitations that prevent them from achieving efficiency when designing the experience of their users and therefore the design of the maturity model Keikendo "path of experience" became necessary. This model addresses the evolution of organizations, focused on the development of digital products, in terms of activities, tools and methods to provide interaction design. Its purpose is to help project teams to incorporate the user into their development strategy, overcoming the difficulties in understanding internal and external clients as part of the same ecosystem with added value to them. For this the model is established from five levels of maturity: 1 - No Intent, 2 - Autoreference, 3 - Expert, 4 - Centralized, and 5 - Distributed (cf. Figure 4).

The companies/organizations that are at the first level are those that focus on product requirements and use words such as usability, web engineering, interaction design, IHC, among other concepts, but do not quite understand how these concepts relate. At the second level, UX is part of the company/organization discourse, but in a simple and fast way where the user often gets confused in the role of the designer himself. In this case, the users are fictitious and generally idealized and for this reason many organizations do not integrate them directly into the design process.

At the third level, UX techniques are incorporated into the processes and there is a person/team with some technical qualification in the area, directing right and wrong, albeit external to the organization. The deficiencies of these levels are in the formalization of processes, that is, UX is incorporate into the product design where there is not a deepening in the process and few techniques of UX are applied due to the unawareness of its use, causing stagnation of the process.

On the fourth level, UX is incorporated into processes where there must be an internal person/team responsible for it. This person/team should have well defined roles and knowledge of a wide range of UX techniques to be applied as needed. The great difficulty of companies that are at this level is the linking of UX metrics to the performance indicators (KPIs) of the company/organization. Only at the fifth level is UX a part of the culture of companies/organizations where all areas are of what UXD is and how it works. From this moment UX is not only seen by the deliverables that it offers, but as a strategic area of the organization. 


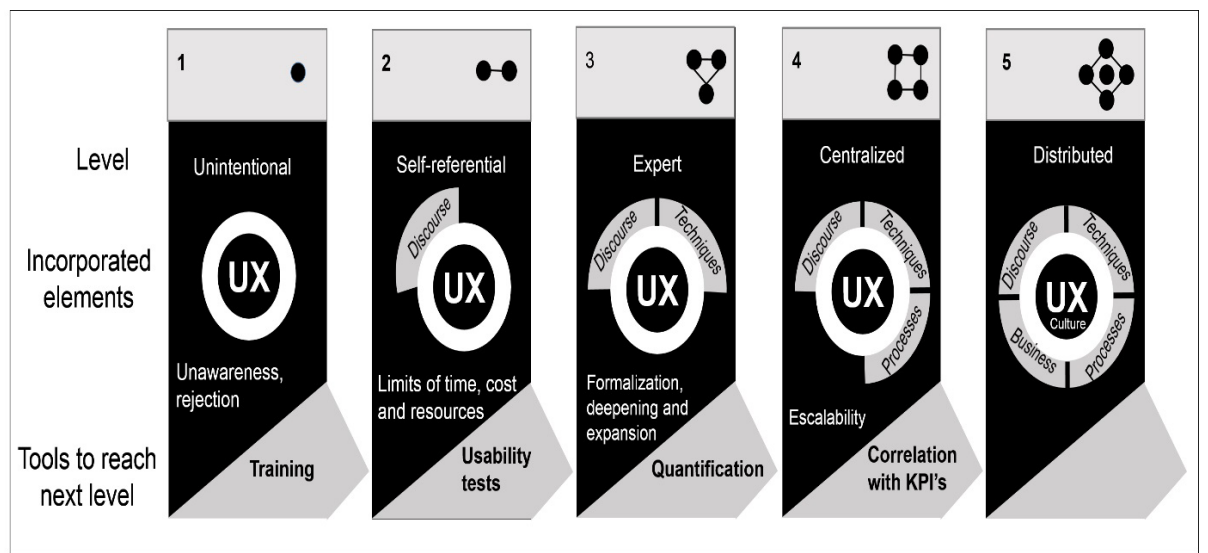

Figure 4. Model Maturity of Keikendo. Source: Adapted of Carraro (2006).

In view of the above, it is verified that several researchers have directed their efforts to consolidate the UX area in different aspects, be it in the UX design process (Hartson \& Pyla, 2012; Unger \& Chandler, 2012), in specific methodologies for UX (Brown, 2013; Gothelf, 2013), in methods for the evaluation of UX (Law et al., 2009; Law et al., 2014) or through maturity models for UX that better target organizations (Carraro, 2006).

However, it is necessary to have a clearer representation of the common design of multidisciplinary teams in UXD. A common language that portrays what constitutes to design for UX in organizations, therefore, as alert Burdek (2006), the verbal descriptions of goals, concepts and solutions are insufficient given the different semantic meanings of terms or concepts used by designers, technicians, and marketing managers (in a development team), which in the national or global context becomes more complex, leading to misunderstandings.

\section{Dynamic systems as representations of knowledge}

System dynamics is a tool of Systemic Thought, made up of the personal domain, mental models, shared vision and learning. These characteristics refer to companies that learn, since the formalization of knowledge in an organizational context, through models, favors their sharing and form the basis of their processes (Jackson, 2003; Senge, 2014).

Madachy (2008) conceptualizes systemic thinking as the art and science of making inferences from an underlying structure, which simultaneously establishes itself as a paradigm and a learning method by adding cognitive skills, processes, languages, and technologies that support the creation of models. From the author's point of view, mental models are, in general, simplifications of reality to obtain answers to certain questions and so are used in everyday life to translate personal or organizational goals into problems, issues and measures.

Although they provide context for interpreting and acting on data or from data from the environment, mental models are rarely explicit. What makes them concrete and evolutionary is their ability to become explicit to the point of being easily understood by people. It is emphasized that the conceptual models give form and visibility to the mental models, since they allow the externalization of knowledge so that it can be understood and evaluated in the face of the choices modeled (Young, 2008).

The modeling is presented as a way of expressing itself through a semantic, while the models produced are interpretations that must satisfy the constraints derived from text, equations, diagrams or other sources of information from the external environment and from the mental analysis of those who solve problems (Greca \& Moreira, 2000; Young, 2008).

Given these assumptions, when modeling and simulation are added, more than technologies are obtained to obtain answers, given the possibility of learning from the structure of models and their sharing associated to the directions obtained by the simulation. The simulation allows to analyze the behavior of the system, on certain conditions or even favors the design of organizational policies, about new decision-making strategies or organizational structures, evaluating their effects in the behavior of the system, according to the problem to be treated (Senge, 2014; Ghinea, 2015).

In dynamic systems, the behavior of the system consists of causal diagrams and inventory and flow diagrams. The first are represented by words that express the concepts of a complex system, connected by arrows that represent their influences. They are very useful for qualitative analyzes, since a large part of the systemic problems can be represented through them, but it is the inventory and flow diagrams that favor the quantitative analyzes when presenting the 
variables, parameters and structure of the system (Amaral, 2012; Amaral et al., 2015).

Under this approach, both causal diagrams and stock and flow diagrams are established as computational models that qualify mental models, on which decisions are based, contributing to the resolution of problems. In addition, dynamic systems portray system variations over time, according to the configuration of its structure and from the outline of the variables that compose it, adding the benefits of simulation that directs observation and analysis of system state changes resulting from this configuration (Madachy, 2008).

Dynamic systems consist of parameters and variables. The parameters are independent measures that configure the inputs and the structure of the system while the variables depend on parameters and other variables, in which the set of them represents a system at a given point in time, that is, they determine the state of the system (Madachy, 2008; Amaral et al., 2015).

The Figure 5 shows a causal diagram (a) and a stock and flow diagram (b), where stocks indicate accumulations of a system, responsible for providing capacity of "memory" to the system, encoded in rectangles with a descriptive name and depict the initial conditions of the system before the simulation. They have intuitive, almost immediate interpretation when they represent: people, number of defects, tasks, day to a delivery of a project. They may represent accumulations of non-physical measures such as stress, knowledge, experience, happiness, among others.

The rates/flows are the elements that move the quantities from one stock to another, because the value of a stock can only be altered when the quantifiable entities move into or out of it by means of a rate/flow, given the variation of a stock relative to a state in time (Barros, 2001). By changing the behavior of the system (during the simulation), rates/flows are responsible for the dynamic behavior of the system. They are interpreted, intuitively, as valves that allow the flow of entities from one stock to another, which justifies their graphic representation in valve form in most of the tools. And the auxiliary variables are variables or constants used as parameters or for indirect calculations (like evaluators), using other elements of the system.

Regarding the simulation of stock and flow diagrams, it is constituted by the numerical resolution of a system of differential equations under initial conditions, where the stocks represent the system level variables while the rates (flows) refer to their differential equations. Thus, the value of a stock, at a given point in time, is determined by the integration of the rates and by the knowledge of its initial value, given by the boundary conditions (Chaim, 2001; Sheard et al., 2015).

It is added that most of the variables present in systemic diagrams are subjective variables, since much of what is known in the world is descriptive, qualitative, difficult to quantify and often not stored before, however such information is crucial for the understanding and modeling of complex systems (Jackson, 2003; Chaim, 2001; Sheard et al., 2015).

Within these designs Chaim (2001) says that there are currently no limits to the inclusion of subjective variables in models, and many simulations include them, even because subjective variables such as desire, product quality, reputation, expectations and optimism are always of critical importance to the decision-making process and fail to consider them in the models only due to the lack of numerical data is less "scientific" than to include them, estimating reasonable values to them (Chaim, 2001).

\section{The systemic modeling of DafetU: methodological procedures}

This section brings the systemic modeling of DAfetU - a hybrid and conceptual Framework directed to the evaluation of the impact of interactive computer systems (Ellwanger et al., 2015), in order to verify which assumptions related to the definition of concepts corresponding to the user experience should be considered, how the modeling can be established (what variables to consider, what to contemplate) and the simulation results resulting from the design decisions. The study was carried out by a multidisciplinary team in the areas of Computation,
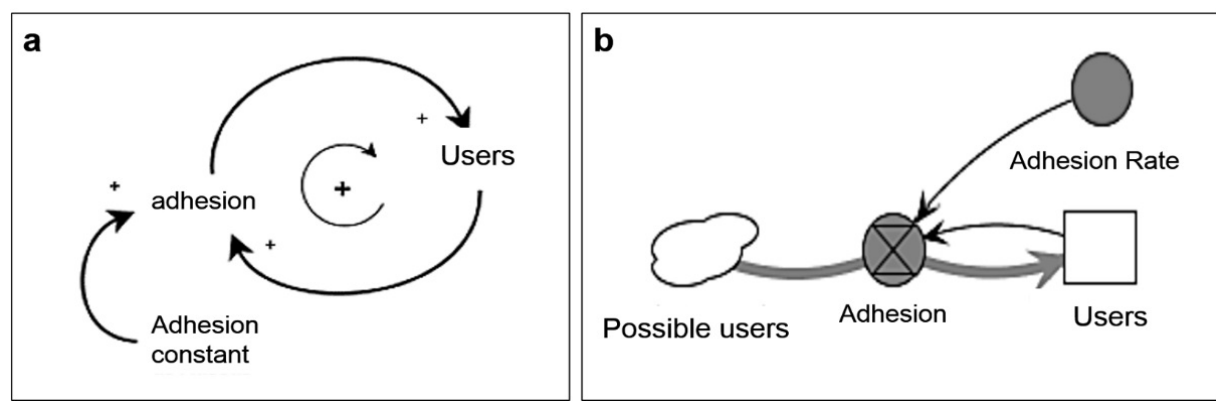

Figure 5. Causal diagram (a), stock and flow diagram (b). Source: Adapted of Madachy (2008). 
Production Engineering and Administration, linked to the Federal University of Rio Grande do Sul (UFRGS), and Federal University of Santa Catarina (UFSC).

As Figure 6 shows, DAfetU adds in itself the theoretical conceptions inherent in Experience Design, Design Thinking and Interaction Design. To adapt them to the dynamics of systems, initially, it was verified how the dimensions of the framework would fit to the systemic modeling. The modeling of Dimension 1 is supported by the theoretical conceptions related to the UX design process, fundamentals and specificities of the dynamic systems area and is established by the designers/devisor/developers reflection on the variables involved in the UX process, its correlations and parameters, which are directly influenced by metrics resulting from UX evaluations (Dimension 2).

Dimension 2 portrays users/clients, intends to seek informational subsidies, in evaluations performed with users that are or have the possibility of converted into metrics in order incorporated into the model. At this stage it is important to know which assessment techniques are used in the organizational scope and which metrics are obtained with their application. In addition, it is necessary to analyze what has not been done in terms of evaluation with users and what should be done to provide systemic modeling. The designs of ability, expertise and knowledge of designers/devisor/developers, lead to simulation and make it possible to check the outputs from the modeled system.

The operation of the simulation (Dimension 3), in functional terms and assignment of the values to the model favors the calibration. The purpose of the calibration is to adapt the structure of the model and to allow the verification of erroneous conceptions, regarding the correlation of variables with the assignment of values corresponding to the parameters. The adjustments are based on the initial consolidation of the model, where simulation, calibration and consolidation establish the visualization of the behavior of the system, from the modeled structure and the establishment of possible scenarios. From them it is possible to see the impacts coming from the structuring of the model.

\section{Results from the work done}

In order to structure DAfetU in systemic modeling, the three dimensions that comprise it, the Designer Dimension (Dimension 1), the User Dimension (Dimension 2) and the Dimension Affectibility (Dimension 3) were considered. The designer dimension reflects the constructs of devisors related to ideation and the experience of the user by the constitution of causal diagrams from the semantic language corresponding to the area of dynamic systems. The user dimension is structured by data, coming from the UX evaluations, and checking how they can be incorporated into the model, so these evaluations are of paramount importance.

Finally, the affectivity dimension is portrayed through the correlations established by designers in the designer dimension, by the data coming from the evaluations and in the structuring assumed by them and established by the simulation. These dimensions portray the configuration and generation activities of the graphical visualization of the computational model in a simulation horizon. For this, specific programs

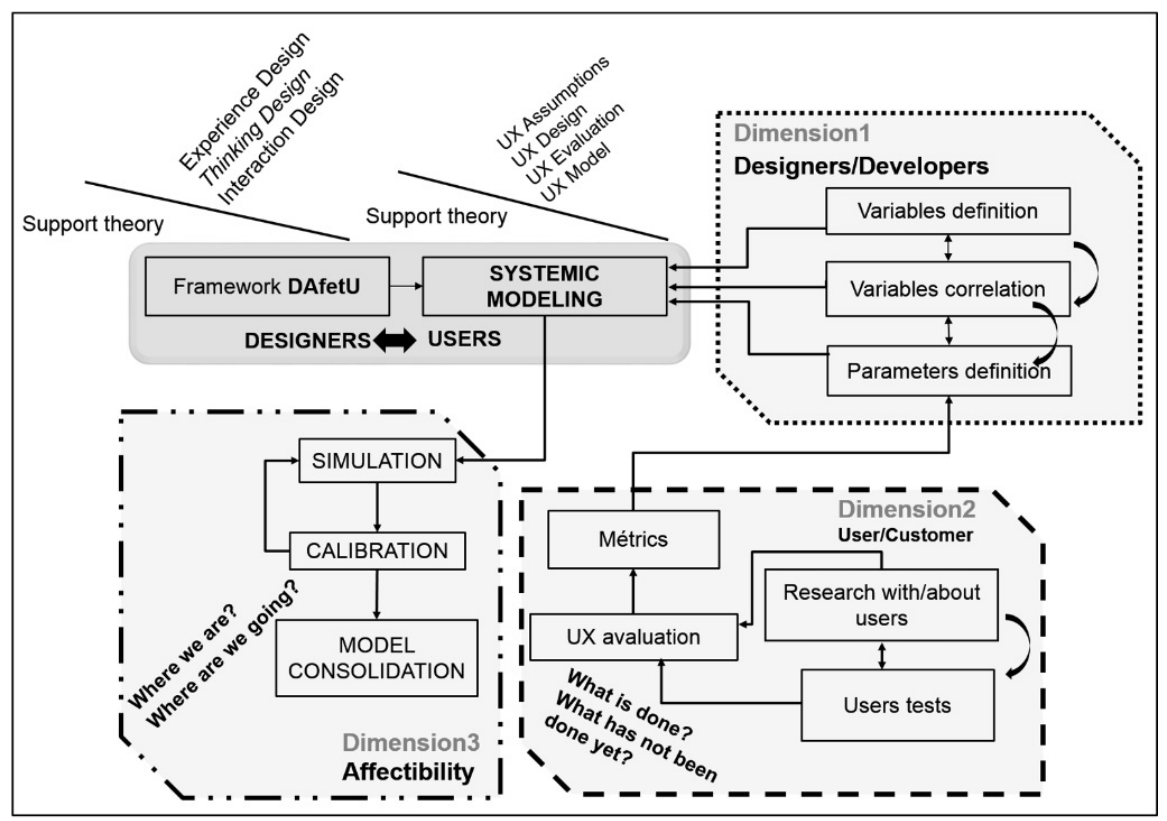

Figure 6. Methodology for systemic modeling. 
are used for the Dynamics of Systems that favor the verification of the impact resulting from theoretical constructs and the correlations established for them. For this research, Vensim ${ }^{\circledR}$ Software - Trademark of Ventana Systems Inc. - PLE (version 6.2) was used.

The structure of the model was conceived from the data of the literature that portrays the design process and the literature specialized in UX that gave subsidy to the composition of the model. Thus, the ideation is contemplated in the modeling, given its importance to the design process and in view of the purpose of establishing a correlation of the same and the user experience in terms of impact (cf. Figure 7).

Such variables defined as level variables, since it intended to verify how construct delineations, related to the ideation in the design process, and affected the constructs related to the user experience. Since the flow variables are those that are directly related to the level variables, that is, they are established as inputs and outputs, they were defined as flow to the specific phases of the ideation, in accordance with the model proposed by Herring et al. (2009), which argues that ideation is a mixture of research, representation and refinement.

For the composition of the model it was also verified that the ideation can be quantified through the variables quantity, variety, innovation and qualityThe parameters for the composition of the model corresponding to these variables depict the amount of ideas generated during design at a specific time, as well as the variety of solutions generated (groupings of ideas). To innovation was considered the mathematical formula $\left(\left(\mathrm{T}_{\mathrm{jk}-} \mathrm{C}_{\mathrm{jk}} / \mathrm{T}_{\mathrm{jk}}\right) \times 10\right)$, where Tjk is the total of generated ideas and $\mathrm{Cjk}$ is set of solutions. Regarding quality, the auxiliary tools support the incorporation of the numerical parameters that constitute it such as the QFD, the Pug Matrix or the Decision Trees (Shah et al., 2003).

In the level variable "user experience", aspects related to positive and negative emotions, perceived values and interaction time were considered, and these are presented as auxiliary variables in the model. In relation to the auxiliary variable "perceived values" were privileged by the parameters described in the work of Pereira \& Baranauskas (2015) in which they present a series of values, their priority, the number of solutions that contemplate them and the number of people who refer them as relevant.

In the parametrization of the auxiliary variable "experience percentage" we considered the number of experienced designers divided by the total number of designers involved in a given project or by the definition of this variable as a lookup type in which oscillations of these percentages vary in a certain period of time. The initial parameters were defined in order to verify the behavior of the system, from the modeled variables and the corresponding relationship between them. From the initial conception, the computational model was incorporated into an interactive interface, in order to provide better visualization of data, scenarios and facilitate data entry in the model, exempting designers/devisor/developers the complexity linked to the simulation and the parameters that give rise to them (cf. Figure 8).

From the modeling and simulation scenario, we opted for a weekly time, similar to the agile methodologies in which the restructuring of designs for the development of computational applications occurs. Thus, the simulation shows how the variables of in "Ideation", and "User Experience" level impact, and

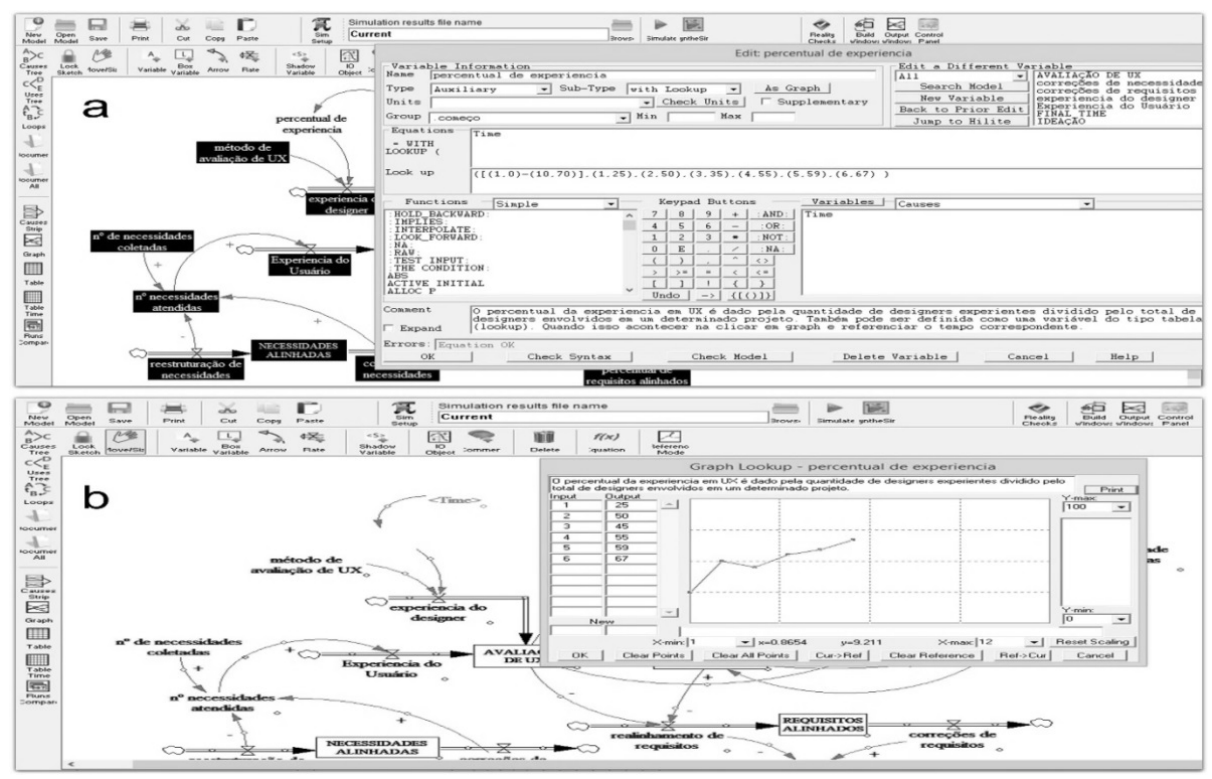

Figure 7. Initial Model - Relation and Correlation between variables (a), and parameters (b). 


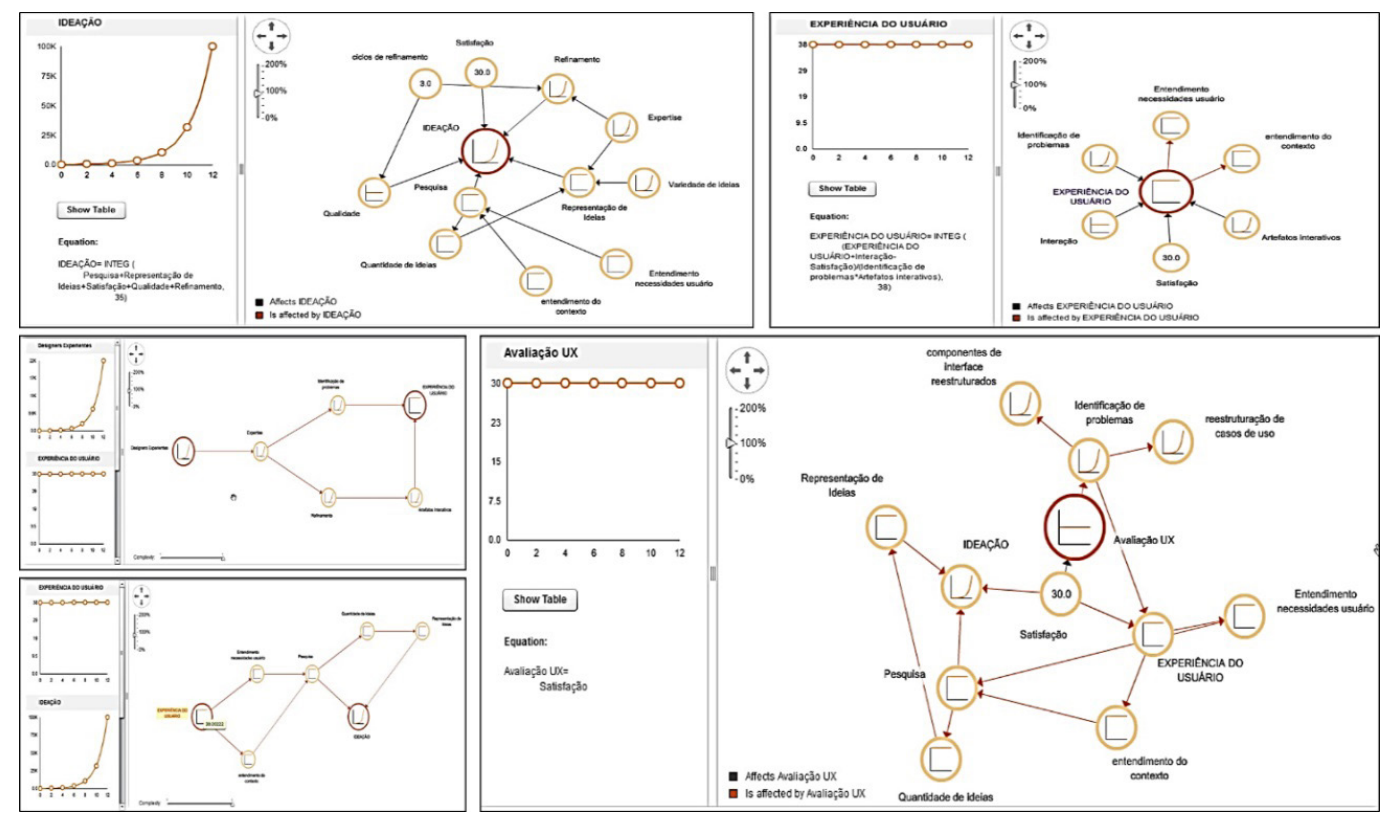

Figure 8. Interactive systemic modeling, and system behavior analysis.

are impacted by the auxiliary variables "experienced designers" and "UX evaluation".

At first, it was found that given a user satisfaction, significantly low $(30 \%$ of $100 \%)$ in relation to the proposed solutions, even with a three-cycle refinement for solution improvement it does not evolve in terms of ideation, this means Ideation only begins to evolve from the sixth week, a significant period of time when working with agile methodologies.

Second, there was a stagnation of the "User Experience" level variable, due to the time it takes for novice designers to become experienced - and thereby bring meaningful solutions to the idea - and the small number of experienced designers integrated into the team. This is due to the techniques used in the ideation and the lack of alternation between the methods used for the UX evaluations, as well as the restrictions of these in terms of information to support the ideation.

Based on the design of the model and its corresponding simulation, proactive decisions can be delineated as training teams to learn new and differentiated methods of UX evaluation, which actually subsidize the ideation in quantitative terms, although it requires time available for this occurs. An alternative would be the integration of new experienced professionals to the team, as they would consequently entail additional costs due to the specialized knowledge of the personnel to be hired. However, this often becomes feasible, especially when you have a short time to complete projects.

The dynamic modeling of this work is not intended to generalize, but to glimpse possible scenarios from the modeled structure. It is appropriate to the objectives of organizations coming from skills, expertise and knowledge of multidisciplinary team (designers/devisor/developers), according to characteristics and peculiarities inherent to the projects in which they work (applications for mobile devices, embedded systems, web applications among others). Other scenarios can be delineated, including checking the structure of the model (given by the associations established between variables), and its behavior.

From the development of this work, we sought to highlight the precepts of Desmet \& Hekkert (2007) which stresses that planning user experiences at the project level requires focus on the user, designer, research and theory, qualifying the practice of design.

\section{Conclusion}

This work shows that the UX area has broad support in the literature that subsidizes the process of designing for user experience, showing a great potential for the establishment of constructs and its design in dynamic and simulated structures. These constructs are reflected in a way to optimize the use of data and excel in an approach that follows the directions of Law et al. (2014) noting that there is much more to be glimpsed in the midst of this significant amount of data coming from evaluations performed with users.

The article also reinforces the importance of contemplating the experience of designers in the process of designing interactive computational solutions, considering the set of decisions that permeate it and the verification of the impact of these decisions on the project as a whole. Therefore, it was tried to demonstrate the initial efforts and directions for the 
validation of DAfetU, since conceptual frameworks lack validation and the dynamic modeling, associated with the simulation, is favorable for this to occur, since both are presented as an alternative to make explicit the tacit knowledge of interdisciplinary teams.

In addition to modeling, the directions in terms of impact presented here suggest a common semantic that portrays what constitutes design for UX in companies/organizations and where one can look at the data and learn from it, favoring reflection about the whole design process as a systemic whole.

By conducting this study that results from theoretical contributions from the literature, systemic modeling can be expanded with the integration of new constructs, related to ideation and experience, and consequently in the delineation of new scenarios from this modeling. In addition, future directions return to the presentation of the model in an organizational context so that it can be reviewed by its idealizers, reviewed by project managers and others involved, and restructured according to the characteristics and specificities of the organizational environment in order to bring a better visibility to the UX design process and its impact on organizational processes.

\section{References}

Amaral, J. A. A. (2012). Desvendando sistemas. São Paulo: Edição do Autor.

Amaral, J. A. A., Gonçalves, P., \& Hess, A. (2015). Creating a project-based learning environment to improve project management skills of graduate students. Journal of Problem Based Learning in Higher Education, 3(2), 120-130.

Barros, M. O.(2001). Gerenciamento de projetos baseado em cenários: uma abordagem de modelagem dinâmica e simulação (Tese de doutorado). Instituto Alberto Luiz Coimbra de Pós-Graduação e Pesquisa de Engenharia, Universidade Federal do Rio de Janeiro, Rio de Janeiro.

Brown, D. M. (2013). Agile user experience design: a practitioner's guide to making it work. Waltham: Elsevier.

Burdek, B. E. (2006). História, teoria e prática do design de produtos. São Paulo: Edgard Blucher.

Calvera, A. (2006). Treinando pesquisadores para o design: algumas considerações e muitas preocupações acadêmicas. Revista Design em Foco, 3(1), 97-120.

Carraro, J. M. (2006). Cómo introducir y hacer madurar la práctica de UX dentro de una organización. Córdova: Interaction South América. Recuperado em 1 de março de 2016, de http://isa.ixda.org/2014/ux-dentro-de-unaorganizacion/

Chaim, R. M. (2001). Modelagem, simulação e dinâmica de sistemas: gestão de segurança da informação $e$ comunicações CEGSIC 2009-2011. Brasília: UnB.
Recuperado em 1 de março de 2016, de http:// creativecommons.org/licenses/by-nc-nd/3.0/br/

Desmet, P., \& Hekkert, P. (2007). Framework of product experience. International Journal of Design, 1(1), 57-66.

Drahun, G. (2016). Visual definitions of user experience. Recuperado em 1 de fevereiro de 2016, de http://www. slideshare.net/Hienadz.Drahun/50-visual-definitionsof-user-experience

Ellwanger, C., Rocha, R. A., \& Silva, R. P. (2015). Design de Interação, Design Experiencial e Design Thinking: a triângulação da Interação Humano-Computador. Revista de Ciências da Administração, 1(1), 26-36. http://dx.doi.org/10.5007/2175-8077.2015v17n43p26.

Ellwanger, C., Silva, R. P., \& Rocha, R. A. (2014). DAfetU: um framework híbrido para avaliação do impacto afetivo de sistemas computacionais interativos. Nuevas Ideas en Informática Educativa TISE, 2014, 1-15.

Esjeholm, B.-T. (2014). Design knowledge interplayed with student creativity in D\&T projects. International Journal of Technology and Design Education, 25(2), 227-243. http://dx.doi.org/10.1007/s10798-014-9280-1.

Fiod, M., No. (1993). Desenvolvimento de sistema computacional para auxiliar a concepção de produtos industriais (Tese de doutorado). Universidade Federal de Santa Catarina, Florianópolis. Recuperado em 1 de fevereiro de 2016, de https://books.google.com.br/ books?id=cpgPtwAACAAJ

Garrett, J. J. (2011). The elements of user experience: user-centered design for the weband beyond (2. ed.). Berkeley: Tracey Croom.

Ghinea, V. M. (2015). Complex systems dynamics and their dynamic simulation: the case of TRUE, Temporal Reasoning Universal Elaboration. In Proceedings of Conference: International Academic Conference on Management, Economics and Marketing. Budapesta.

Gothelf, J. (2013). Lean UX-applying lean principles to improve user experience. Sebastopol: O'Reilly Media.

Greca, I. M., \& Moreira, M. A. (2000). Mental models, conceptual models, and modelling. International Journal of Science Education, 22(1), 1-11. http://dx.doi. org/10.1080/095006900289976.

Hartson, R., \& Pyla, P. S. (2012). The UX Book: Process and guidelines for ensuring a quality user experience. San Diego: Elsevier.

Hayashi, E. C. S., \& Baranauskas, C. M. C. (2013). The affectibility concept in systems for learning contexts. International Journal for e-Learning Security, 1(1-2), 10-18.

Herring, S. R., Jones, B. R., \& Bailey, B. P. (2009). Idea generation techniques among creative professionals. In Proceedings of the 42nd Hawaii International Conference on System Sciences (pp. 1-10). Hawaii. 
International Organization for Standardization - ISO. (1999). ISO 13407: human-centred design processes for interactive systems. Geneva: ISO.

Jackson, M. C. (2003). Systems thinking: creative holism for managers. Chichester: Wiley.

Karapanos, E. (2013). User experience over time. In E. Karapanos, Modeling users'experiences with interactive systems (pp. 57-83). Berlin: Springer Heidelberg.

King, R., \& Churchill, E. F. (2015). Designing with data. Sebastopol: O'Reilly Media.

Law, E. L.-C., Roto, V., Hassenzahl, M., Vermeeren, A. P. O. S., \& Kort, J. (2009). Understanding, scoping and defining user experience: a survey approach. In Proceedings of the SIGCHI Conference on Human Factors in Computing Systems (pp. 719-728). Boston.

Law, E. L.-C., Van Schaik, P., \& Roto, V. (2014). Attitudes towards user experience (UX) measurement. International Journal of Human-Computer Studies, 72(6), 526-541. http://dx.doi.org/10.1016/j.ijhcs.2013.09.006.

Madachy, R. (2008). Software process dynamics. Hoboken: IEEE Press Wiley-InterScience.

Morin, E. (2000). A cabeça bem-feita: repensar a reforma, reformar o pensamento. Rio de Janeiro: Bertand Brasil.

Munari, B. (1998). Das coisas nascem coisas. São Paulo: Martins Fontes.

Ostrower, F. (1990). Acasos e criação artística. Rio de Janeiro: Campus.

Pereira, R., \& Baranauskas, M. C. C. (2015). A valueoriented and culturally informed approach to the design of interactive systems. International Journal of Human-Computer Studies, 80, 66-82. http://dx.doi. org/10.1016/j.ijhcs.2015.04.001.

Senge, P. M. (2014). The fifth discipline fieldbook: strategies and tools for building a learning organization. Crown Business.

Shah, J. J., Smith, S. M., \& Vargas-Hernandez, N. (2003). Metrics for measuring ideation effectiveness. Design Studies, 24(2), 111-134. http://dx.doi.org/10.1016/ S0142-694X(02)00034-0.

Sheard, S., Ferguson, R., Moore, A. P., \& Phillips, M. (2015). A dynamic model of sustainment. Technical Report, CMU/SEI-2015-TR-00. Pittsburgh: Software Solutions Division, Carnegie Mellon University, Recuperado em 1 de fevereiro de 2016, de http://www.sei.cmu.edu

Suh, N. P. (1990). The principles of design. Nova Iorque: Oxford University Press.

Unger, R., \& Chandler, C. (2012). A project guide to ux design: for user experience designers in the field or in the making. Berkeley: New Riders.

Walsh, I. (2014). A strategic path to study IT use through users' IT culture and IT needs: a mixed-method grounded theory. The Journal of Strategic Information Systems, 23(2), 146-173. http://dx.doi.org/10.1016/j. jsis.2013.06.001.

Welch, R. V., \& Dixon, J. R. (1992). Representing function, behavior and structure during conceptual design (pp. 11-18). New York: ASME.

Woods, R., Rafferty, K., Murphy, J., \& Hermon, P. (2014). Engineering innovative products: a practical experience. Chichester: John Wiley \& Sons.

Young, I. (2008). Mental models: aligning design strategy with human behavior. New York: Rosenfeld Media. 